\title{
A Incidência Final dos Impostos Indiretos no Brasil: Efeitos da Tributação de Insumos*
}

\author{
Rozane Bezerra de Siqueira** \\ José Ricardo Nogueira** \\ Evaldo Santana de Souza***
}

Sumário: 1. Introdução; 2. Métodos de cálculo da incidência final de impostos indiretos; 3. Dados; 4. Resultados; 5. Comentários finais. Palavras-chave: impostos indiretos; tributação de insumos; incidência.

Códigos JEL: H22; D3.

Devido à multiplicidade de impostos e alíquotas e à incidência sobre insumos, o efeito final do sistema brasileiro de impostos indiretos sobre os preços está longe de ser transparente. Usando um método que incorpora os efeitos multissetoriais dos impostos indiretos, este artigo calcula, para o Brasil, a incidência efetiva destes impostos sobre os diferentes componentes da demanda final. Os resultados mostram que atividades para as quais existe uma política explícita de desoneração de impostos são de fato significativamente tributadas, indicando que a incidência final pode ser bem diversa daquela defendida pelos formuladores de políticas tributárias ou desejada pela sociedade.

Due to the multiplicity of taxes and rates and to the incidence on inputs, the final effect of the Brazilian indirect tax system on prices is far from transparent. Using a method that incorporates the multisector effects of indirect taxes, this paper calculates, for Brazil, the effective incidence of these taxes on the different components of final demand. The results show that activities for which there is an explicit exemption policy are in fact significantly taxed, indicating that the final incidence may be quite different from that advocated by tax policy makers or wished by society.

\footnotetext{
* Este artigo recebido em jun. 1999 e aprovado em out. 2000, faz parte de um estudo mais amplo sobre os efeitos distributivos dos impostos indiretos no Brasil, conduzido dentro do Grupo de Pesquisa em Economia do Setor Público, Departamento de Economia, Universidade Federal de Pernambuco. Também participaram na elaboração do artigo, como assistentes de pesquisa, os bolsistas Minéya Helga Novaes Santos e Hugo Matheus Aguiar. Os autores desejam agradecer a Rosanna Scutella, do Melbourne Institute of Applied Economic and Social Research, University of Melbourne, Austrália, por esclarecimentos dados quanto ao método utilizado em Scutella (1997), e a um parecerista anônimo por sugestões que contribuíram para melhorar a apresentação do artigo. Todos os erros remanescentes são de responsabilidade dos autores.

** Professores e pesquisadores do Departamento de Economia da UFPE.

*** Doutorando em Economia do Pimes/UFPE.
}

RBE Rio de Janeiro 55(4):513-544 OUT./DEZ. 2001 


\section{Introdução}

Impostos indiretos são aqueles cobrados de produtores com relação à produção, venda, compra ou uso de bens e serviços. ${ }^{1}$ Frequentemente, impostos indiretos são arrecadados em vários estágios do processo de produção e venda, de forma que seus efeitos sobre os preços pagos pelo consumidor final na cadeia de transações não são claros. O efeito final sobre os preços depende não apenas da medida em que os impostos são transferidos para a frente em cada estágio de produção, mas também da estrutura precisa das transações interindustriais.

No Brasil, os impostos indiretos respondem por mais da metade da receita tributária total. ${ }^{2}$ A matriz de insumo-produto brasileira, elaborada pelo Instituto Brasileiro de Geografia e Estatística (IBGE), apresenta o montante de receita líquida arrecadada de cada indústria (ou setor de atividade) pelos principais impostos indiretos. Esta informação, que será aqui denominada de incidência estatutária, mostra quem é legalmente responsável pelo recolhimento do imposto e transferência para o governo. Ela não mostra quem realmente arca com a carga final do imposto, visto que cada indústria pode transferir sua carga inicial para outras indústrias compradoras e/ou consumidores finais através de aumentos de preços.

O objetivo deste artigo é investigar a incidência final (ou econômica) dos impostos indiretos no Brasil usando um método, proposto por Chisholm (1993) e estendido por Scutella (1997), que incorpora os efeitos multissetoriais destes impostos. Este método supõe que os impostos indiretos são totalmente transferidos para a frente em cada estágio da cadeia de produção até o comprador final. ${ }^{3}$ A incidência final em reais e as correspondentes alíquotas efetivas dos principais impostos são aqui calculadas, a partir da matriz de insumo-produto de 1995, para 42 setores de atividade e para cada categoria de demanda final: famílias, governo, investimento e exportação.

\footnotetext{
${ }^{1}$ Vale observar que aqui, assim como na maioria da literatura tributária moderna, o uso do termo indireto para classificar um imposto não envolve nenhuma pressuposição quanto à incidência final do imposto. $O$ que se tem em mente é a definição adotada em Atkinson (1977:592): "[D]irect taxes may be adjusted to the individual characteristics of the tax payer, whereas indirect taxes are levied on transactions irrespective of the circumstances of buyer or seller (...) the only way in which sales taxes can be related to circumstances is indirectly via the differences in consumption patterns".

${ }^{2}$ Incluindo as contribuições sociais.

${ }^{3}$ Esta é uma hipótese-padrão na literatura empírica, como será comentado na seção 2.
} 
Há dois motivos básicos para calcular impostos efetivos. O primeiro é considerá-los um resumo de um sistema tributário complexo, que contribui para que o governo tenha uma idéia mais clara dos efeitos sobre os bens finais de suas diversas medidas na área tributária. O segundo é avaliar os efeitos de reformas nos impostos indiretos sobre a receita do governo e sobre o bemestar das famílias, o que requer informação acerca do impacto destes impostos sobre os preços dos bens e serviços finais. Este artigo diz respeito ao primeiro motivo e gera uma base para uma posterior análise de reformas.

Do nosso conhecimento, apenas Sampaio de Souza (1996) estima impostos indiretos efetivos para o Brasil. Nesse estudo, utilizando um método proposto por Ahmad e Stern (1987 e 1991) e dados de 1980, a autora calcula alíquotas efetivas para 27 atividades produtivas.

O método aqui utilizado e aquele empregado por Sampaio de Souza (1996) se baseiam nas mesmas hipóteses sobre o funcionamento da economia, que implicam transferência integral dos impostos indiretos para os consumidores. $\mathrm{O}$ método adotado neste artigo, no entanto, apresenta duas vantagens principais.

Primeiro, permite levar em conta o fato de que algumas indústrias são isentas de alguns tipos de impostos, e esta isenção se aplica também à compra de seus insumos diretos. Assim, tais indústrias sofrem apenas os efeitos indiretos associados à tributação de insumos em outras indústrias não-isentas. Isto é importante, por exemplo, quando se avalia a incidência de um imposto que é, em princípio, sobre o valor agregado, mas que "falha" em conceder rebate do imposto pago sobre insumos para algum setor na rede de produção e comercialização.

Segundo, por separar a incidência direta da incidência indireta no cálculo da incidência final total dos impostos, o método usado neste artigo permite estimar a carga tributária efetiva para cada componente da demanda final. Observe que a incidência sobre famílias, governo, investimento e exportação não depende apenas da participação de cada uma destas categorias na demanda final, mas também de possíveis isenções legais. Por exemplo, deve-se levar em conta que o governo é isento da incidência direta de impostos.

Adicionalmente, as estimativas aqui apresentadas diferem das de Sampaio de Souza por incorporar na tributação de bens de consumo final o efeito atribuível à tributação de bens de capital. ${ }^{4}$

\footnotetext{
${ }^{4}$ Vale ressaltar que o modelo de curto prazo utilizado por Sampaio de Souza (1996) pode ser estendido para captar o efeito da tributação de bens de capital (Ahmad \& Stern, 1991).
} 
Além desta introdução, este artigo é composto de mais quatro seções. A seção 2 descreve o método de cálculo da incidência efetiva dos impostos indiretos sobre a demanda final. Os dados utilizados na aplicação para o Brasil são descritos na seção 3. A seção 4 apresenta e discute os resultados obtidos. Por último, a seção 5 apresenta as considerações finais.

\section{Método de Cálculo da Incidência Final de Impostos Indiretos}

Seguindo o procedimento usual na análise empírica de impostos indiretos, o método proposto em Chisholm (1993) e Scutella (1997) supõe que estes impostos são transferidos totalmente para os consumidores. ${ }^{5}$ Esta hipótese é consistente para uma economia com mercados competitivos, cuja tecnologia de produção apresenta retornos constantes de escala, onde não há produção conjunta e há apenas um insumo não-produzido. ${ }^{6}$ Sem dúvida, esta é uma circunstância bastante especial. De modo geral, a direção e o grau de transferência de impostos indiretos dependem da tecnologia de produção, das elasticidades da oferta e da demanda para o bem tributado e para os fatores de produção e da estrutura do mercado onde os impostos são cobrados.

A endogenização da transferência dos impostos em um estudo de incidência requer, portanto, a especificação de um modelo completo de equilíbrio geral e a determinação de parâmetros que, em geral, não estão disponíveis, pelo menos no nível de agregação de uma matriz de insumo-produto padrão. Esta é certamente uma das principais razões por que as análise de incidência adotam a hipótese da transferência integral dos impostos indiretos para consumidores. ${ }^{7}$ Por outro lado, Stern (1987) e Ahmad e Stern (1991), por exemplo, defendem esta hipótese, lembrando que em modelos não-competitivos a transferência pode ser acima de $100 \%$ e, portanto, é possível que a transferência de $100 \%$ seja uma hipótese intermediária razoável, e não um caso extremo, como pode

\footnotetext{
${ }^{5}$ Ver, entre outros, Pechman (1985), Creedy (1998), Engel et alii (1998) e Younger (1999). Estudos de incidência para o Brasil também seguem esta convenção (Eris et alii, 1983; Sanson, 1984; Souza, 1996).

${ }^{6}$ Neste caso, o teorema da não-substituição se aplica, e os preços de produtor são determinados unicamente pela tecnologia (ver, por exemplo, Mas-Colell, Whiston \& Green, 1995).

${ }^{7}$ Como argumenta Whalley (1984:678), "In building an explicit general equilibrium model, the 'arbitrariness' of shifting assumptions is, to some extent, replaced by the 'arbitrariness' of choice of elasticities and model form".
} 
parecer. ${ }^{8}$ Vale também notar que a matriz de insumo-produto, que é a base do método aqui utilizado, adota esta hipótese no tratamento dos impostos. ${ }^{9}$

Por ser baseado na matriz de insumo-produto, o método permite captar os efeitos da tributação direta e indireta de insumos. Isto significa, por exemplo, que no caso de um imposto sobre gasolina, levam-se em conta tanto os efeitos sobre os preços para os consumidores diretos de gasolina e para os consumidores de transporte público, quanto os efeitos indiretos quando o transporte é um produto intermediário.

O método básico descrito em Chisholm (1993) e Scutella (1997) pode ser aplicado em um modelo de curto prazo ou de longo prazo. Os dois modelos se diferenciam quanto ao tratamento dado aos componentes variação de estoque, formação bruta de capital fixo e excedente operacional bruto da matriz de insumo-produto. No modelo de curto prazo, devido à hipótese usual de que o estoque de capital é fixo, a coluna variação de estoque é suprimida da demanda final. No modelo de longo prazo, relaxa-se a hipótese de invariância do estoque de capital, com a coluna variação de estoque permanecendo na demanda final. Por sua vez, a coluna formação bruta de capital fixo e a linha excedente operacional bruto são adicionadas à demanda intermediária na matriz de insumo-produto. Isto envolve a suposição de que os impostos indiretos que incidem inicialmente sobre a formação bruta de capital fixo são transferidos para a frente através do aumento de preços para os bens e serviços adquiridos por compradores finais para consumo ou exportação. ${ }^{10}$

Os cálculos apresentados neste artigo são baseados no modelo de longo prazo. A seguir descrevemos o método, que envolve estes passos:

- calcular a incidência estatutária;

- calcular a incidência de primeiro estágio sobre a demanda intermediária e sobre a demanda final;

\footnotetext{
${ }^{8}$ Segundo Brown e Jackson (1994:515), estudos de incidência de impostos sobre bens e serviços "typically start by assuming that the taxes in question are fully shifted forward, i.e. that prices rise by just the amount of the tax". Por sua vez, McLure (1990:36), discutindo hipóteses de incidência tributária, afirma que "assumptions about the incidence of many taxes are conventional and noncontroversial. Such is the case especially for indirect taxes, which ordinarily can reasonably be attributable to consumers".

${ }^{9}$ Note, ainda, que este tratamento é consistente com a hipótese de tecnologia de Leontief, na qual a construção da matriz é baseada.

${ }^{10}$ A hipótese implícita sobre o padrão de acumulação temporal é de steady state; caso contrário, teríamos de considerar o efeito de impostos cobrados em um período sobre os preços em todos os outros períodos, o que requer um modelo dinâmico totalmente articulado.
} 
- calcular a incidência de estágios subseqüentes sobre a demanda final;

- calcular a incidência final total e as alíquotas efetivas de imposto por categoria de demanda final.

\subsection{Cálculo da incidência estatutária}

A incidência estatutária dos impostos indiretos sobre a atividade $i, I E_{i}$, que representa a receita efetivamente arrecadada pelo governo daquela atividade, consiste na soma da incidência estatutária dos vários tipos de impostos indiretos $t$ sobre a atividade $i$, ou seja:

$$
I E_{i}=\sum_{t=1}^{n} E I_{i t} \quad \text { para } i=1, \cdots, m \text { e } t=1, \cdots, n
$$

\subsection{Cálculo da incidência de primeiro estágio}

Supõe-se que as indústrias transferem totalmente os impostos indiretos pagos ao governo para as indústrias compradoras e para a demanda final. A transferência para as indústrias compradoras representa a incidência de primeiro estágio sobre a demanda intermediária, IDI.

Na mensuração da transferência para a demanda intermediária, deve-se levar em consideração o fato de que algumas indústrias são isentas de alguns tipos de impostos. Para tanto, utiliza-se uma matriz de coeficientes de produção não-isenta, AN. Esta matriz é construída a partir da matriz completa de fluxos intersetoriais, mas com os fluxos entre indústrias isentas igualados a zero. Ela expressa a oferta intermediária não-isenta de um bem ou serviço da indústria $i$ para a indústria compradora $j$ como uma percentagem da oferta total não-isenta daquele bem ou serviço.

A incidência de primeiro estágio sobre a demanda intermediária é, então, obtida multiplicando-se o vetor de incidência estatutária pela matriz de coeficientes de produção não-isenta, isto é:

$$
I D I^{\prime}=I E^{\prime} \times A N
$$

Algumas indústrias sujeitas a impostos indiretos vendem produtos ou serviços diretamente para famílias, governo ou consumidores estrangeiros. 
Nesse caso, o imposto é transferido para a demanda final no primeiro estágio. A incidência de primeiro estágio sobre a demanda final, IDF, é obtida multiplicando-se, para cada indústria $i$, a incidência estatutária pela demanda final não-isenta, $D F N$ (que exclui as categorias de demanda final isentas), como porcentagem da oferta total não-isenta, OTN, ou seja:

$$
I D F_{i}=I E_{i}\left(D F N_{i} / O T N_{i}\right) \quad \text { para } i=1, \cdots, m
$$

\subsection{Cálculo da incidência de estágios subseqüentes}

Em cada estágio da cadeia de produção, uma parcela do produto de uma indústria será comprada por consumidores finais e o restante será usado por outras indústrias como insumo para sua produção, a qual, por sua vez, será ofertada ou para a demanda final ou para outras indústrias, e assim sucessivamente. Eventualmente, depois de muitos estágios, todo insumo acabará na demanda final, e, dada a nossa hipótese de transferência total dos impostos indiretos em cada estágio, todo imposto incidirá sobre a demanda final.

Em cada estágio, a parcela de imposto sobre a indústria $i$ que é transferida para a demanda final, $Z_{i}$, é obtida dividindo-se a demanda final pela oferta total:

$$
Z_{i}=D F_{i} / O T_{i} \quad \text { para } i=1, \cdots, m
$$

Portanto, o montante de imposto transferido para a demanda final no estágio corrente é obtido multiplicando-se $Z_{i}$ pelo montante de imposto que permaneceu sobre a indústria $i$ no estágio anterior.

Para se calcular o montante de imposto que permanece sobre a demanda intermediária em cada estágio, utiliza-se a matriz de coeficientes técnicos, $A$, que não permite isenções, uma vez que aquelas indústrias que são isentas de um dado imposto somente obtêm o benefício da isenção para impostos sobre seus insumos diretos, não para impostos sobre insumos para seus insumos.

O montante de imposto que permanece sobre a demanda intermediária é $I D I^{\prime} \times I$ no estágio $2, I D I^{\prime} \times A$ no estágio $3, I D I^{\prime} \times A^{2}$ no estágio 4 e $I D I^{\prime} \times A^{n-2}$ no estágio $n$. Depois de $n+2$ estágios, o montante de imposto transferido para a demanda final, isto é, a incidência de estágios subseqüentes, IES, é dado por:

$I E S=\left(I D I^{\prime} \times I\right)^{\prime} \# Z+\left(I D I^{\prime} \times A\right)^{\prime} \# Z+\left(I D I^{\prime} \times A^{2}\right)^{\prime} \# Z+\cdots+\left(I D I^{\prime} \times A^{n}\right)^{\prime} \# Z$ 
onde o símbolo \# se refere à multiplicação elemento por elemento, e não à multiplicação matricial.

A expressão acima pode ser reescrita como:

$$
I E S=\left[I D I^{\prime} \times\left(I+A+A^{2}+\cdots+A_{n}\right)\right]^{\prime} \# Z
$$

Quando $n$ é infinito, a expressão entre parênteses é uma série geométrica infinita, que pode ser simplificada para:

$$
I E S=\left[I D I^{\prime} \times(I-A)^{-1}\right]^{\prime} \# Z
$$

\subsection{Cálculo da incidência final}

A incidência final total dos impostos indiretos, $I F T$, é a soma da incidência de primeiro estágio sobre a demanda final e a incidência de estágios subseqüentes. Portanto,

$$
I F T_{i}=I D F_{i}+I E S_{i} \quad \text { para } i=1, \cdots, m
$$

Para se calcular a incidência final sobre cada componente da demanda final, utiliza-se a participação de cada componente na demanda final total, $D F$, e na demanda final não-isenta, $D F N$. Assim, por exemplo, se $X$ denotar exportações e $X N$ as exportações não-isentas, então a incidência final total sobre exportações, IFTX, é dada por:

$$
\operatorname{IFTX}_{i}=\operatorname{IDF}_{i}\left(X N_{i} / D F N_{i}\right)+\operatorname{IE} S_{i}\left(X_{i} / D F_{i}\right) \quad \text { para } i=1, \cdots, m
$$

Por último, as alíquotas efetivas correspondentes são obtidas dividindo-se a incidência final do imposto pelo nível de despesa de cada componente da demanda final.

\section{Dados}

Os principais dados requeridos para a realização dos cálculos descritos na seção anterior são a receita arrecadada por cada imposto, classificada por atividade, e tabelas de coeficientes de insumo-produto para usos de bens e 
serviços. Requer-se, ainda, informação sobre isenções legais e concessões de rebates, para cada tipo de imposto.

Neste artigo, utilizamos a matriz de insumo-produto/Brasil 1995 (IBGE, 1997). A Matriz apresenta informação sobre a receita líquida que o governo arrecada de cada atividade produtiva, para cada uma das seguintes categorias de impostos: imposto sobre circulação de mercadorias e serviços (ICMS), imposto sobre produtos industrializados e imposto sobre serviços (IPI/ISS), imposto sobre importações (II) e outros impostos. Para estes impostos, a Matriz também apresenta dados da incidência de primeiro estágio sobre a demanda intermediária e sobre a demanda final, nas tabelas denominadas "Destino dos impostos". Portanto, para os impostos discriminados na Matriz, não foram necessários os procedimentos descritos nas seções 2.1 e 2.2 para se calcular a incidência final dos mesmos. ${ }^{11}$

Outras informações necessárias para o cálculo da incidência de estágios subseqüentes são obtidas a partir da tabela "Usos de bens e serviços" da matriz. A incidência final dos impostos foi estimada para 42 atividades produtivas, de acordo com a classificação (das colunas) da matriz de insumoproduto. $^{12}$

\section{Resultados}

A tabela 1 apresenta a incidência estatutária dos principais impostos indiretos no Brasil em 1995, ou seja, a receita líquida (ou efetiva) arrecadada pelo governo de cada atividade produtiva naquele ano. Observe que, dado que partimos da receita efetivamente arrecadada, nossos cálculos levam em conta os rebates de impostos pagos sobre insumos, no caso de impostos sobre valor adicionado, assim como a evasão fiscal e o efeito-cascata de alguns impostos. Devido à limitação de espaço, os resultados para a incidência de primeiro estágio, a incidência final e as alíquotas efetivas são apresentados apenas para todos os impostos indiretos conjuntamente e para o ICMS, o qual representa cerca de $65 \%$ da arrecadação total. ${ }^{13}$

\footnotetext{
${ }^{11}$ Obviamente, para impostos não incluídos na Matriz, o cálculo da incidência final dos mesmos envolve tais procedimentos.

${ }^{12}$ Observe que as linhas da Matriz adotam uma classificação mais desagregada das atividades. Porém, para tornar a Matriz quadrada, foi necessário agregar as atividades de acordo com a classificação das colunas.

${ }^{13}$ Os interessados nos resultados para os demais impostos podem solicitá-los aos autores.
} 
Tabela 1

Incidência estatutária: impostos indiretos (em R \$ mil) - Brasil, 1995

\begin{tabular}{lrrrrr}
\hline Atividade & ICMS & IPI/ISS & II & $\begin{array}{c}\text { Outros } \\
\text { impostos }\end{array}$ & Total \\
\hline Agropecuária & & & & & \\
Extrativa mineral & 2.128 .469 & 0 & 55.477 & 70.190 & 2.254 .136 \\
Extração de petróleo e gás & 75.738 & 916 & 3.205 & 14.099 & 93.958 \\
Minerais não-metálicos & 28.473 & 0 & 282.970 & 116.858 & 428.301 \\
Siderurgia & 2.972 .721 & 594.770 & 33.549 & 8.203 & 3.609 .243 \\
Metalurgia não-ferrosos & 183.027 & 253.693 & 28.900 & 15.800 & 481.420 \\
Outros metalúrgicos & 223.952 & 186.571 & 47.540 & 25.480 & 483.543 \\
Máquinas e tratores & 1.605 .875 & 875.258 & 75.547 & 14.418 & 2.571 .098 \\
Material elétrico & 991.092 & 1.052 .187 & 455.898 & 114.361 & 2.613 .538 \\
Equipamentos eletrônicos & 1.415 .218 & 987.862 & 214.484 & 55.034 & 2.672 .598 \\
Automóveis, caminhões e ônibus & 1.474 .524 & 648.700 & 483.137 & 107.498 & 2.713 .859 \\
Outros veículos e peças & 2.956 .023 & 581.294 & 1.441 .773 & 55.927 & 5.035 .017 \\
Madeira e mobiliário & 1.523 .901 & 596.390 & 234.552 & 85.136 & 2.439 .979 \\
Papel e gráfica & 1.092 .800 & 268.919 & 13.308 & 3.774 & 1.378 .801 \\
Indústria da borracha & 1.289 .365 & 738.910 & 31.162 & 24.482 & 2.083 .919 \\
Elementos químicos & 787.059 & 426.170 & 54.371 & 18.628 & 1.286 .228 \\
Refino do petróleo & 129.196 & 0 & 87.463 & 118.876 & 335.535 \\
Químicos diversos & 1.440 .839 & 99.931 & 369.659 & 279.394 & 2.189 .823 \\
Farmacêutica e perfumaria & 713.004 & 499.116 & 96.865 & 45.690 & 1.354 .675 \\
Artigos de plástico & 2.144 .326 & 760.776 & 78.068 & 28.844 & 3.012 .014 \\
Indústria textil & 693.927 & 464.954 & 70.029 & 11.104 & 1.240 .014 \\
Artigos do vestuário & 1.478 .852 & 7.963 & 167.616 & 31.437 & 1.685 .868 \\
\hline
\end{tabular}


Tabela 1

Incidência estatutária: impostos indiretos (em R \$ mil) - Brasil, 1995

\begin{tabular}{lrrrrr} 
continuação & \multicolumn{1}{c}{ Total } \\
\hline Atividade & ICMS & IPI/ISS & II & $\begin{array}{c}\text { Outros } \\
\text { impostos }\end{array}$ & Tres \\
\hline Fabricação de calçados & 822.057 & 21.578 & 71.637 & 9.800 & 925.072 \\
Indústria do café & 405.377 & 0 & 98 & 994 & 406.469 \\
Beneficiamento de produtos vegetais & 1.417 .803 & 2.406 .271 & 27.878 & 261.021 & 4.112 .973 \\
Abate de animais & 2.153 .845 & 3.067 & 3.586 & 6.493 & 2.166 .991 \\
Indústria de laticínios & 1.217 .731 & 0 & 71.118 & 10.038 & 1.298 .887 \\
Indústria de açúcar & 558.800 & 0 & 114 & 533 & 559.447 \\
Fabricação de óleos vegetais & 493.423 & 0 & 7.171 & 9.776 & 510.370 \\
Outros produtos alimentares & 4.362 .769 & 1.354 .985 & 91.026 & 33.643 & 5.842 .423 \\
Indústrias diversas & 2.428 .856 & 737.425 & 225.993 & 46.484 & 3.438 .758 \\
Serviços industriais de utilidade pública & 3.177 .170 & 0 & 0 & 0 & 3.177 .170 \\
Construção civil & 0 & 313.856 & 0 & 0 & 313.856 \\
Comércio & 0 & 131.631 & 0 & 90 & 131.721 \\
Transportes & 1.026 .971 & 238.482 & 0 & 138.997 & 1.404 .450 \\
Comunicaçães & 1.908 .354 & 1.631 & 0 & 13 & 1.909 .998 \\
Instituições financeiras & 0 & 173.989 & 0 & 2.465 .647 & 2.639 .636 \\
Serviços prestados às famílias & 1.083 .692 & 1.098 .991 & 0 & 543.953 & 2.726 .636 \\
Serviços prestados às empresas & 0 & 1.065 .189 & 0 & 633 & 1.065 .822 \\
Aluguel de imóveis & 0 & 2.671 & 0 & 0 & 2.671 \\
Administração pública & 0 & 0 & 0 & 0 & 0 \\
Serviços privados não-mercantis & 0 & 0 & 0 & 0 & 0 \\
\hline Total & 48.072 .215 & 16.647 .368 & 4.875 .955 & 4.777 .896 & 74.373 .434 \\
\hline
\end{tabular}

Fonte: IBGE (1997). 
As incidências de primeiro estágio para todos os impostos indiretos e para o ICMS são apresentadas nas tabelas 2 e 3, respectivamente. As alíquotas implícitas correspondentes estão nas tabelas 4 e 5 . As alíquotas de impostos apresentadas neste artigo são calculadas dividindo-se a incidência do imposto pela demanda incluindo o imposto. Inicialmente, os impostos indiretos recaem, quase na mesma proporção, sobre a demanda intermediária (49\%) e sobre a demanda final (51\%). Em relação a esta última, 93,5\% dos impostos incidem sobre o consumo das famílias. Para o ICMS, isoladamente, estes percentuais são $45 \%, 56 \%$ e $94 \%$, respectivamente. Observe, ainda, que o consumo da administração pública é isento de impostos no primeiro estágio, e que a incidência sobre as exportações, de forma geral, é relativamente baixa. ${ }^{14}$

Dada a nossa hipótese de que os impostos indiretos são totalmente transferidos para a frente em cada estágio da cadeia de mercado, no longo prazo, a incidência final dos mesmos recai apenas sobre o consumo final, não havendo qualquer incidência sobre a demanda intermediária. As tabelas 6 e 7 mostram a incidência final, em reais, de todos os impostos indiretos e do ICMS, respectivamente, enquanto as tabelas 8 e 9 apresentam as alíquotas efetivas correspondentes.

A partir das tabelas 6 e 7, observa-se que, apesar de a incidência final dos impostos ser principalmente sobre o consumo das famílias $-84 \%$ do total de impostos e $86 \%$ do ICMS -, as exportações e a administração pública também pagam um montante significativo de impostos indiretos. A comparação dessas tabelas com as tabelas 2 e 3 indica que a tributação daquelas duas últimas categorias da demanda final é essencialmente uma conseqüência da tributação de insumos, e não um resultado intencional da política do governo. Deve-se observar que o resultado negativo para a atividade "extração de petróleo e gás" na última coluna das tabelas 6 e 7 reflete a incidência tributária sobre a variação de estoque, que, neste caso, é negativa. O sinal negativo deve ser interpretado como um imposto que não foi arrecadado no ano de referência (1996), mas em um período anterior quando o estoque foi formado. ${ }^{15}$

\footnotetext{
${ }^{14}$ As alíquotas sobre exportações de produtos agropecuários e de produtos vegetais beneficiados são altas. No entanto, devemos chamar a atenção para o fato de que a Lei Complementar $n^{\circ}$ 87 (Lei Kandir), de 13 de setembro de 1996, desonera o ICMS incidente sobre as exportações de produtos primários e semi-elaborados e possibilita rebater o ICMS pago nas compras de bens de capital e material de consumo não utilizado diretamente no processo produtivo. Portanto, a partir do momento em que essas medidas passaram a vigorar, a incidência de primeiro estágio do ICMS sobre as exportações tende a ser nula.

${ }^{15}$ Observe que o item "variação de estoque" está incluído no total da demanda final.
} 
Tabela 2

Incidência de primeiro estágio: todos os impostos (em R\$ mil) - Brasil, 1995

\begin{tabular}{|c|c|c|c|c|c|}
\hline \multirow[b]{2}{*}{ Atividade } & \multirow[b]{2}{*}{$\begin{array}{c}\text { Consumo } \\
\text { intermediário }\end{array}$} & \multicolumn{4}{|c|}{ Demanda final } \\
\hline & & $\overline{\text { Exportação }}$ & $\begin{array}{c}\text { Consumo da } \\
\text { administração } \\
\text { pública }\end{array}$ & $\begin{array}{c}\text { Consumo } \\
\text { das } \\
\text { famílias }\end{array}$ & Total \\
\hline Agropecuária & 912.386 & 214.350 & 0 & 1.108 .106 & 1.341 .750 \\
\hline Extrativa mineral & 72.392 & 4.526 & 0 & 0 & 21.566 \\
\hline Extração de petróleo e gás & 435.987 & 719 & 0 & 0 & -7.686 \\
\hline Minerais não-metálicos & 3.190 .061 & 1.265 & 0 & 354.766 & 419.182 \\
\hline Siderurgia & 352.810 & 8.878 & 0 & 0 & 128.610 \\
\hline Metalurgia não-ferrosos & 284.431 & 7.474 & 0 & 96.127 & 199.112 \\
\hline Outros metalúrgicos & 2.003 .965 & 2.153 & 0 & 516.286 & 567.133 \\
\hline Máquinas e tratores & 2.656 .933 & 8.760 & 0 & 10.723 & -43.395 \\
\hline Material elétrico & 1.463 .576 & 8.708 & 0 & 1.124 .727 & 1.209 .022 \\
\hline Equipamentos eletrônicos & 1.471 .912 & 3.666 & 0 & 1.173 .161 & 1.241 .947 \\
\hline Automóveis, caminhões e ônibus & 1.362 .590 & 11.416 & 0 & 3.618 .131 & 3.672 .427 \\
\hline Outros veículos e peças & 1.922 .558 & 33.872 & 0 & 425.421 & 517.421 \\
\hline Madeira e mobiliário & 580.669 & 1.311 & 0 & 783.556 & 798.132 \\
\hline Papel e gráfica & 1.608 .773 & 3.534 & 0 & 467.053 & 475.146 \\
\hline Indústria da borracha & 1.167 .673 & 2.139 & 0 & 70.785 & 118.555 \\
\hline Elementos químicos & 235.258 & 5.835 & 0 & 95.643 & 100.277 \\
\hline Refino do petróleo & 1.851 .793 & 15.773 & 0 & 240.103 & 338.030 \\
\hline Químicos diversos & 1.207 .085 & 4.996 & 0 & 61.734 & 147.590 \\
\hline Farmacêutica e perfumaria & 583.821 & 1.122 & 0 & 2.399 .847 & 2.428 .193 \\
\hline Artigos de plástico & 934.514 & 735 & 0 & 176.731 & 305.500 \\
\hline Indústria textil & 660.604 & 32.269 & 0 & 905.841 & 1.025 .264 \\
\hline Artigos do vestuário & 12.516 & 173 & 0 & 1.763 .794 & 1.764 .001 \\
\hline
\end{tabular}


Tabela 2

Incidência de primeiro estágio: todos os impostos (em R\$ mil) - Brasil, 1995

continuação

\begin{tabular}{|c|c|c|c|c|c|}
\hline \multirow[b]{2}{*}{ Atividade } & \multirow[b]{2}{*}{$\begin{array}{c}\text { Consumo } \\
\text { intermediário }\end{array}$} & \multicolumn{4}{|c|}{ Demanda final } \\
\hline & & $\overline{\text { Exportação }}$ & $\begin{array}{l}\text { Consumo da } \\
\text { administração } \\
\text { pública }\end{array}$ & $\begin{array}{l}\text { Consumo } \\
\text { das } \\
\text { famílias }\end{array}$ & Total \\
\hline Fabricação de calçados & 51.831 & 3.418 & 0 & 844.398 & 873.241 \\
\hline Indústria do café & 45.366 & 154.708 & 0 & 206.786 & 361.103 \\
\hline Beneficiamento de produtos vegetais & 186.504 & 446.773 & 0 & 3.461 .084 & 3.926 .469 \\
\hline Abate de animais & 245.613 & 2.114 & 0 & 1.842 .429 & 1.921 .378 \\
\hline Indústria de laticínios & 150.703 & 163 & 0 & 1.129.702 & 1.148 .184 \\
\hline Indústria de açúcar & 159.012 & 383 & 0 & 437.721 & 400.435 \\
\hline Fabricação de óleos vegetais & 61.097 & 147.006 & 0 & 291.488 & 449.273 \\
\hline Outros produtos alimentares & 1.851 .672 & 1.950 & 0 & 3.913 .134 & 3.990 .751 \\
\hline Indústrias diversas & 1.734 .720 & 3.347 & 0 & 1.667 .759 & 1.704 .038 \\
\hline Serviços industriais de utilidade pública & 1.857 .472 & 0 & 0 & 1.319 .698 & 1.319 .698 \\
\hline Construção civil & 313.856 & 0 & 0 & 0 & 0 \\
\hline Comércio & 126.142 & 5.579 & 0 & 0 & 5.579 \\
\hline Transportes & 594.813 & 27.024 & 0 & 782.613 & 809.637 \\
\hline Comunicações & 876.035 & 17 & 0 & 1.033 .946 & 1.033 .963 \\
\hline Instituições financeiras & 1.900 .493 & 17.569 & 0 & 721.574 & 739.143 \\
\hline Serviços prestados às famílias & 450.792 & 4.164 & 0 & 2.271 .680 & 2.275 .844 \\
\hline Serviços prestados às empresas & 1.005 .047 & 34.374 & 0 & 26.400 & 60.775 \\
\hline Aluguel de imóveis & 1.032 & 0 & 0 & 1.639 & 1.639 \\
\hline Administração pública & 0 & 0 & 0 & 0 & 0 \\
\hline Serviços privados não-mercantis & 0 & 0 & 0 & 0 & 0 \\
\hline Total & 36.584 .508 & 1.222 .263 & 0 & 35.344 .588 & 37.788 .926 \\
\hline
\end{tabular}

Obs.: O "total" da demanda final inclui o item "variação de estoque". Portanto, asoma dos componentes da demanda final apresentados na tabela pode não coincidir com o resultado da coluna "total". 
Tabela 3

Incidência de primeiro estágio: ICMS (em R $\$$ mil) - Brasil, 1995

\begin{tabular}{|c|c|c|c|c|c|}
\hline \multirow[b]{2}{*}{ Atividade } & \multirow[b]{2}{*}{$\begin{array}{c}\text { Consumo } \\
\text { intermediário }\end{array}$} & \multicolumn{4}{|c|}{ Demanda final } \\
\hline & & Exportação & $\begin{array}{c}\text { Consumo da } \\
\text { administração } \\
\text { pública }\end{array}$ & $\begin{array}{c}\text { Consumo } \\
\text { das } \\
\text { famílias }\end{array}$ & Total \\
\hline Agropecuária & 826.664 & 210.150 & 0 & 1.083 .278 & 1.301 .805 \\
\hline Extrativa mineral & 58.870 & 0 & 0 & 0 & 16.868 \\
\hline Extração de petróleo e gás & 28.357 & 116 & 0 & 0 & 116 \\
\hline Minerais não-metálicos & 2.627 .238 & 0 & 0 & 293.277 & 345.483 \\
\hline Siderurgia & 131.150 & 2.688 & 0 & 0 & 51.877 \\
\hline Metalurgia não-ferrosos & 121.014 & 0 & 0 & 51.635 & 102.938 \\
\hline Outros metalúrgicos & 1.245 .741 & 0 & 0 & 329.095 & 360.134 \\
\hline Máquinas e tratores & 1.018 .907 & 0 & 0 & 6.035 & -27.815 \\
\hline Material elétrico & 749.498 & 0 & 0 & 620.013 & 665.720 \\
\hline Equipamentos eletrônicos & 661.924 & 0 & 0 & 781.122 & 812.600 \\
\hline Automóveis, caminhões e ônibus & 1.029 .606 & 0 & 0 & 1.888 .747 & 1.926 .417 \\
\hline Outros veículos e peças & 1.180 .276 & 0 & 0 & 301.204 & 343.625 \\
\hline Madeira e mobiliário & 461.752 & 0 & 0 & 620.381 & 631.048 \\
\hline Papel e gráfica & 1.009.703 & 0 & 0 & 276.756 & 279.662 \\
\hline Indústria da borracha & 718.368 & 0 & 0 & 41.051 & 68.691 \\
\hline Elementos químicos & 53.722 & 0 & 0 & 78.226 & 75.474 \\
\hline Refino do petróleo & 1.197 .441 & 0 & 0 & 181.753 & 243.398 \\
\hline Químicos diversos & 625.679 & 0 & 0 & 38.883 & 87.325 \\
\hline Farmacêutica e perfumaria & 310.132 & 0 & 0 & 1.814 .058 & 1.834 .194 \\
\hline Artigos de plástico & 517.718 & 0 & 0 & 102.766 & 176.209 \\
\hline Indústria textil & 509.056 & 30.815 & 0 & 860.021 & 969.796 \\
\hline Artigos do vestuário & 11.275 & 0 & 0 & 1.655 .678 & 1.655 .711 \\
\hline
\end{tabular}


Tabela 3

Incidência de primeiro estágio: ICMS (em R $\$$ mil) - Brasil, 1995

continuação

\begin{tabular}{lrrrrr}
\hline Atividade & Consumo & \multicolumn{4}{c}{ Demanda final } \\
\cline { 3 - 7 } & Entermediário & & $\begin{array}{c}\text { Exportação } \\
\text { administração } \\
\text { pública }\end{array}$ & $\begin{array}{c}\text { Consumo } \\
\text { das } \\
\text { famílias }\end{array}$ & Total \\
\hline Fabricação de calçados & 17.175 & 0 & 0 & 780.212 & 804.882 \\
Indústria do café & 45.316 & 153.728 & 0 & 206.724 & 360.061 \\
Beneficiamento de produtos vegetais & 97.472 & 131.666 & 0 & 1.190 .503 & 1.320 .331 \\
Abate de animais & 243.039 & 0 & 0 & 1.834 .370 & 1.910 .806 \\
Indústria de laticínios & 127.165 & 0 & 0 & 1.073 .064 & 1.090 .566 \\
Indústria de açúcar & 158.843 & 0 & 0 & 437.617 & 399.957 \\
Fabricação de óleos vegetais & 51.879 & 142.935 & 0 & 288.175 & 441.544 \\
Outros produtos alimentares & 1.322 .295 & 0 & 0 & 2.992 .621 & 3.040 .474 \\
Indústrias diversas & 1.147 .594 & 0 & 0 & 1.256 .452 & 1.281 .262 \\
Serviços industriais de utilidade pública & 1.857 .472 & 0 & 0 & 1.319 .698 & 1.319 .698 \\
Construção civil & 0 & 0 & 0 & 0 & 0 \\
Comércio & 0 & 0 & 0 & 0 & 0 \\
Transportes & 477.165 & 0 & 0 & 549.806 & 549.806 \\
Comunicações & 875.161 & 0 & 0 & 1.033 .193 & 1.033 .193 \\
Instituições financeiras & 0 & 0 & 0 & 0 & 0 \\
Serviços prestados às famílias & 194.713 & 0 & 0 & 888.979 & 888.979 \\
Serviços prestados às empresas & 0 & 0 & 0 & 0 & 0 \\
Aluguel de imóveis & 0 & 0 & 0 & 0 & 0 \\
Administração pública & 0 & 0 & 0 & 0 & 0 \\
Serviços privados não-mercantis & 0 & 0 & 0 & 0 & 0 \\
\hline Total & 21.709 .380 & 672.099 & 0 & 24.875 .392 & 26.362 .835 \\
\hline
\end{tabular}

Obs.: O "total" da demanda final inclui o item "variação de estoque". Portanto, asoma dos componentes da demanda final apresentados na tabela pode não coincidir com o resultado da coluna "total". 
Tabela 4

Alíquotas de primeiro estágio: todos os impostos indiretos (\%) - Brasil, 1995

\begin{tabular}{|c|c|c|c|c|c|}
\hline \multirow[b]{2}{*}{ Atividade } & \multirow[b]{2}{*}{$\begin{array}{c}\text { Consumo } \\
\text { intermediário }\end{array}$} & \multicolumn{4}{|c|}{ Demanda final } \\
\hline & & Exportação & $\begin{array}{c}\text { Consumo da } \\
\text { administração } \\
\text { pública }\end{array}$ & $\begin{array}{l}\text { Consumo } \\
\text { das } \\
\text { famílias }\end{array}$ & Total \\
\hline Extrativa mineral & 1,3 & 0,2 & 0 & 0,0 & 0,6 \\
\hline Extração de petróleo e gás & 5,3 & 1,4 & 0 & 0,0 & 6,8 \\
\hline Minerais não-metálicos & 17,4 & 0,2 & 0 & 25,6 & 19,3 \\
\hline Metalurgia não-ferrosos & 3,3 & 0,4 & 0 & 26,5 & 7,1 \\
\hline Outros metalúrgicos & 9,4 & 0,3 & 0 & 24,4 & 18,4 \\
\hline Máquinas e tratores & 8,9 & 0,4 & 0 & 9,3 & $-3,1$ \\
\hline Material elétrico & 13,5 & 0,6 & 0 & 18,2 & 15,0 \\
\hline Equipamentos eletrônicos & 10,3 & 0,5 & 0 & 10,3 & 9,9 \\
\hline Automóveis, caminhões e ônibus & 12,9 & 0,9 & 0 & 19,2 & 18,0 \\
\hline Indústria da borracha & 14,1 & 0,4 & 0 & 31,5 & 12,9 \\
\hline Elementos químicos & 2,6 & 0,9 & 0 & 2,9 & 2,5 \\
\hline Refino do petróleo & 4,1 & 0,8 & 0 & 2,2 & 2,3 \\
\hline Químicos diversos & 6,6 & 0,8 & 0 & 8,3 & 8,7 \\
\hline Farmacêutica e perfumaria & 17,2 & 0,4 & 0 & 16,8 & 16,5 \\
\hline Artigos de plástico & 10,6 & 0,3 & 0 & 20,7 & 18,2 \\
\hline Indústria textil & 4,3 & 2,8 & 0 & 19,3 & 16,3 \\
\hline Artigos do vestuário & 5,9 & 0,1 & 0 & 13,2 & 13,0 \\
\hline
\end{tabular}


Tabela 4

Alíquotas de primeiro estágio: todos os impostos indiretos (\%) - Brasil, 1995

continuação

\begin{tabular}{|c|c|c|c|c|c|}
\hline \multirow[b]{2}{*}{ Atividade } & \multirow[b]{2}{*}{$\begin{array}{c}\text { Consumo } \\
\text { intermediário }\end{array}$} & \multicolumn{4}{|c|}{ Demanda final } \\
\hline & & $\overline{\text { Exportação }}$ & $\begin{array}{c}\text { Consumo da } \\
\text { administração } \\
\text { pública }\end{array}$ & $\begin{array}{c}\text { Consumo } \\
\text { das } \\
\text { famílias }\end{array}$ & Total \\
\hline Fabricação de calçados & 3,8 & 0,2 & 0 & 21,0 & 14,5 \\
\hline Indústria do café & 1,9 & 6,8 & 0 & 6,8 & 6,8 \\
\hline Beneficiamento de produtos vegetais & 3,2 & 18,0 & 0 & 19,2 & 19,0 \\
\hline Abate de animais & 5,0 & 0,2 & 0 & 10,4 & 9,8 \\
\hline Indústria de laticínios & 5,1 & 2,9 & 0 & 12,2 & 12,2 \\
\hline Indústria de açúcar & 5,3 & 0,0 & 0 & 23,9 & 11,6 \\
\hline Fabricação de óleos vegetais & 1,0 & 4,9 & 0 & 7,8 & 6,5 \\
\hline Outros produtos alimentares & 15,0 & 0,2 & 0 & 16,5 & 15,9 \\
\hline Indústrias diversas & 19,4 & 0,5 & 0 & 23,1 & 21,3 \\
\hline Serviços industriais de utilidade pública & 8,4 & 0,0 & 0 & 12,5 & 12,5 \\
\hline Construção civil & 0,3 & 0,0 & 0 & 0,0 & 0,0 \\
\hline Comércio & 1,6 & 1,6 & 0 & 0,0 & 1,6 \\
\hline Transportes & 3,8 & 0,8 & 0 & 6,2 & 5,1 \\
\hline Comunicações & 13,5 & 0,1 & 0 & 18,5 & 18,4 \\
\hline Instituições financeiras & 12,7 & 7,0 & 0 & 5,5 & 5,5 \\
\hline Serviços prestados às famílias & 2,6 & 0,4 & 0 & 3,6 & 3,6 \\
\hline Serviços prestados às empresas & 2,7 & 2,7 & 0 & 2,7 & 2,7 \\
\hline Aluguel de imóveis & 0,0 & 0,0 & 0 & 0,0 & 0,0 \\
\hline Administração pública & 0,0 & 0,0 & 0 & 0,0 & 0,0 \\
\hline Serviços privados não-mercantis & 0,0 & 0,0 & 0 & 0,0 & 0,0 \\
\hline Total & 3,9 & 2,5 & 0,0 & 9,1 & 6,6 \\
\hline
\end{tabular}

não coincidir com o resultado da coluna "total". 
Tabela 5

Alíquotas de primeiro estágio: ICMS (\%) - Brasil, 1995

\begin{tabular}{|c|c|c|c|c|c|}
\hline \multirow[b]{2}{*}{ Atividade } & \multirow[b]{2}{*}{$\begin{array}{c}\text { Consumo } \\
\text { intermediário }\end{array}$} & \multicolumn{4}{|c|}{ Demanda final } \\
\hline & & Exportação & $\begin{array}{c}\text { Consumo da } \\
\text { administração } \\
\text { pública }\end{array}$ & $\begin{array}{l}\text { Consumo } \\
\text { das } \\
\text { famílias }\end{array}$ & Total \\
\hline Agropecuária & 1,3 & 19,2 & 0 & 4,1 & 4,2 \\
\hline Extrativa mineral & 1,1 & 0,0 & 0 & 0,0 & 0,5 \\
\hline Extração de petróleo e gás & 0,3 & 0,2 & 0 & 0,0 & $-0,1$ \\
\hline Minerais não-metálicos & 14,4 & 0,0 & 0 & 21,2 & 15,9 \\
\hline Siderurgia & 0,7 & 0,1 & 0 & 0,0 & 1,2 \\
\hline Metalurgia não-ferrosos & 1,4 & 0,0 & 0 & 14,2 & 3,7 \\
\hline Outros metalúrgicos & 5,8 & 0,0 & 0 & 15,6 & 11,7 \\
\hline Máquinas e tratores & 3,4 & 0,0 & 0 & 5,3 & $-2,0$ \\
\hline Material elétrico & 6,9 & 0,0 & 0 & 10,0 & 8,3 \\
\hline Equipamentos eletrônicos & 4,6 & 0,0 & 0 & 6,9 & 6,5 \\
\hline Automóveis, caminhões e ônibus & 9,8 & 0,0 & 0 & 10,0 & 9,4 \\
\hline Outros veículos e peças & 5,7 & 0,0 & 0 & 11,8 & 5,6 \\
\hline Madeira e mobiliário & 5,8 & 0,0 & 0 & 9,5 & 8,0 \\
\hline Papel e gráfica & 4,7 & 0,0 & 0 & 6,8 & 4,2 \\
\hline Indústria da borracha & 8,7 & 0,0 & 0 & 18,2 & 7,5 \\
\hline Elementos químicos & 0,6 & 0,0 & 0 & 2,4 & 1,9 \\
\hline Refino do petróleo & 2,7 & 0,0 & 0 & 1,6 & 1,6 \\
\hline Químicos diversos & 3,4 & 0,0 & 0 & 5,2 & 5,2 \\
\hline Farmacêutica e perfumaria & 9,1 & 0,0 & 0 & 12,7 & 12,5 \\
\hline Artigos de plástico & 5,9 & 0,0 & 0 & 12,0 & 10,5 \\
\hline Indústria textil & 3,3 & 2,7 & 0 & 18,3 & 15,4 \\
\hline Artigos do vestuário & 5,3 & 0,0 & 0 & 12,4 & 12,2 \\
\hline
\end{tabular}


Tabela 5

Alíquotas de primeiro estágio: ICMS (\%) - Brasil, 1995

continuação

\begin{tabular}{|c|c|c|c|c|c|}
\hline \multirow[b]{2}{*}{ Atividade } & \multirow[b]{2}{*}{$\begin{array}{c}\text { Consumo } \\
\text { intermediário }\end{array}$} & \multicolumn{4}{|c|}{ Demanda final } \\
\hline & & Exportação & $\begin{array}{l}\text { Consumo da } \\
\text { administração } \\
\text { pública }\end{array}$ & $\begin{array}{c}\text { Consumo } \\
\text { das } \\
\text { famílias }\end{array}$ & Total \\
\hline Fabricação de calçados & 1,3 & 0,0 & 0 & 19,4 & 13,3 \\
\hline Indústria do café & 1,9 & 6,8 & 0 & 6,8 & 6,8 \\
\hline Beneficiamento de produtos vegetais & 1,7 & 5,3 & 0 & 6,6 & 6,4 \\
\hline Abate de animais & 4,9 & 0,0 & 0 & 10,3 & 9,7 \\
\hline Indústria de laticínios & 4,3 & 0,0 & 0 & 11,6 & 11,6 \\
\hline Indústria de açúcar & 5,3 & 0,0 & 0 & 23,9 & 11,6 \\
\hline Fabricação de óleos vegetais & 0,9 & 4,8 & 0 & 7,7 & 6,4 \\
\hline Outros produtos alimentares & 10,7 & 0,0 & 0 & 12,6 & 12,1 \\
\hline Indústrias diversas & 12,8 & 0,0 & 0 & 17,4 & 16,0 \\
\hline Serviços industriais de utilidade pública & 8,4 & 0,0 & 0 & 12,5 & 12,5 \\
\hline Construção civil & 0,0 & 0,0 & 0 & 0,0 & 0,0 \\
\hline Comércio & 0,0 & 0,0 & 0 & 0,0 & 0,0 \\
\hline Transportes & 3,0 & 0,0 & 0 & 4,4 & 3,4 \\
\hline Comunicações & 13,5 & 0,0 & 0 & 18,5 & 18,4 \\
\hline Instituições financeiras & 0,0 & 0,0 & 0 & 0,0 & 0,0 \\
\hline Serviços prestados às famílias & 1,1 & 0,0 & 0 & 1,4 & 1,4 \\
\hline Serviços prestados às empresas & 0,0 & 0,0 & 0 & 0,0 & 0,0 \\
\hline Aluguel de imóveis & 0,0 & 0,0 & 0 & 0,0 & 0,0 \\
\hline Administração pública & 0,0 & 0,0 & 0 & 0,0 & 0,0 \\
\hline Serviços privados não-mercantis & 0,0 & 0,0 & 0 & 0,0 & 0,0 \\
\hline Total & 2,3 & 1,4 & 0,0 & 6,4 & 4,6 \\
\hline
\end{tabular}

não coincidir com o resultado da coluna "total". 
Tabela 6

Incidência final: todos os impostos indiretos ( $\mathrm{R} \$$ mil) - Brasil, 1995

\begin{tabular}{lrrrr}
\hline Atividade & Exportação & $\begin{array}{c}\text { Consumo da } \\
\text { administração } \\
\text { pública }\end{array}$ & $\begin{array}{c}\text { Consumo } \\
\text { das } \\
\text { famílias }\end{array}$ & $\begin{array}{c}\text { Total } \\
\text { demanda } \\
\text { final }\end{array}$ \\
\hline Agropecuária & 279.799 & 0 & 2.670 .490 & 3.179 .040 \\
Extrativa mineral & 179.116 & 0 & 0 & 218.491 \\
Extração de petróleo e gás & 5.438 & 0 & 0 & -17.940 \\
Minerais não-metálicos & 124.751 & 0 & 667.920 & 911.566 \\
Siderurgia & 355.704 & 0 & 0 & 509.726 \\
Metalurgia não-ferrosos & 188.676 & 0 & 127.573 & 443.004 \\
Outros metalúrgicos & 110.047 & 0 & 810.930 & 997.460 \\
Máquinas e tratores & 289.176 & 0 & 26.366 & 148.832 \\
Material elétrico & 203.743 & 0 & 1.991 .345 & 2.334 .563 \\
Equipamentos eletrônicos & 74.194 & 0 & 2.295 .086 & 2.479 .612 \\
Automóveis, caminhões e ônibus & 147.993 & 0 & 5.674 .766 & 5.906 .660 \\
Outros veículos e peças & 456.683 & 0 & 766.472 & 1.329 .316 \\
Madeira e mobiliário & 110.613 & 0 & 1.335 .190 & 1.468 .553 \\
Papel e gráfica & 299.616 & 0 & 944.202 & 1.253 .386 \\
Indústria da borracha & 111.244 & 0 & 115.836 & 303.044 \\
Elementos químicos & 52.895 & 0 & 337.597 & 390.991 \\
Refino do petróleo & 160.244 & 0 & 1.085 .718 & 1.482 .784 \\
Químicos diversos & 80.890 & 0 & 148.555 & 344.615 \\
Farmacêutica e perfumaria & 22.900 & 0 & 3.435 .965 & 3.497 .589 \\
Artigos de plástico & 31.579 & 0 & 296.883 & 542.363 \\
Indústria textil & 139.395 & 0 & 1.348 .085 & 1.618 .847 \\
Artigos do vestuário & 6.315 & 0 & 2.347 .599 & 2.353 .960 \\
\hline
\end{tabular}


Tabela 6

Incidência final: todos os impostos indiretos ( $\mathrm{R} \$$ mil) - Brasil, 1995

continuação

\begin{tabular}{lrrrr}
\hline Atividade & Exportação & $\begin{array}{c}\text { Consumo da } \\
\text { administração } \\
\text { pública }\end{array}$ & $\begin{array}{c}\text { Consumo } \\
\text { das } \\
\text { famílias }\end{array}$ & $\begin{array}{c}\text { Total } \\
\text { demanda } \\
\text { final }\end{array}$ \\
\hline Fabricação de calçados & 120.091 & 0 & 1.092 .942 & 1.246 .317 \\
Indústria do café & 250.365 & 0 & 335.418 & 585.148 \\
Beneficiamento de produtos vegetais & 565.997 & 0 & 4.325 .110 & 4.918 .678 \\
Abate de animais & 66.370 & 0 & 2.748 .244 & 2.924 .494 \\
Indústria de latićnios & 432 & 0 & 1.577 .621 & 1.604 .023 \\
Indústria de açúcar & 148.749 & 0 & 590.126 & 688.090 \\
Fabricação de óleos vegetais & 327.850 & 0 & 517.608 & 864.550 \\
Outros produtos alimentares & 94.883 & 0 & 6.052 .818 & 6.256 .376 \\
Indústrias diversas & 88.669 & 0 & 2.594 .139 & 2.734 .033 \\
Serviços industriais de utilidade pública & 0 & 0 & 2.423 .867 & 2.423 .867 \\
Construção civil & 0 & 0 & 0 & 0 \\
Comércio & 162.561 & 0 & 0 & 162.561 \\
Transportes & 350.814 & 0 & 1.962 .477 & 2.313 .291 \\
Comunicações & 3.500 & 0 & 1.626 .721 & 1.630 .221 \\
Instituições financeiras & 53.635 & 0 & 2.613 .816 & 2.667 .451 \\
Serviços prestados às famílias & 50.864 & 0 & 5.236 .629 & 5.287 .493 \\
Serviços prestados às empresas & 100.048 & 0 & 76.651 & 176.700 \\
Aluguel de imóveis & 99 & 0 & 2.414 .501 & 2.414 .601 \\
Administração pública & 0 & 3.724 .807 & 200 & 3.725 .007 \\
Serviços privados não-mercantis & 0 & 0 & 54.071 & 54.071 \\
\hline Total & 5.815 .937 & 3.724 .807 & 62.669 .537 & 74.373 .434 \\
\hline
\end{tabular}

Obs.: O "total" da demanda final inclui o item "variação de estoque". Portanto, asoma dos componentes da demanda final apresentados na tabela pode não coincidir com o resultado da coluna "total". 
Tabela 7

Incidência final: ICMS (em R\$ mil) - Brasil, 1995

\begin{tabular}{lrrrr}
\hline Atividade & Exportação & $\begin{array}{c}\text { Consumo da } \\
\text { administração } \\
\text { pública }\end{array}$ & $\begin{array}{c}\text { Consumo } \\
\text { das } \\
\text { famílias }\end{array}$ & $\begin{array}{c}\text { Total } \\
\text { demanda } \\
\text { final }\end{array}$ \\
\hline Agropecuária & 251.471 & 0 & 2.069 .691 & 2.461 .780 \\
Extrativa mineral & 101.658 & 0 & 0 & 131.530 \\
Extração de petróleo e gás & 1.308 & 0 & 0 & -2.475 \\
Minerais não-metálicos & 95.928 & 0 & 536.543 & 727.980 \\
Siderurgia & 176.476 & 0 & 0 & 242.847 \\
Metalurgia não-ferrosos & 93.742 & 0 & 67.903 & 229.112 \\
Outros metalúrgicos & 63.730 & 0 & 503.132 & 614.315 \\
Máquinas e tratores & 125.937 & 0 & 13.060 & 58.516 \\
Material elétrico & 102.843 & 0 & 1.076 .983 & 1.259 .222 \\
Equipamentos eletrônicos & 34.437 & 0 & 1.328 .938 & 1.416 .930 \\
Automóveis, caminhões e ônibus & 88.249 & 0 & 3.217 .638 & 3.370 .063 \\
Outros veículos e peças & 250.191 & 0 & 503.015 & 824.050 \\
Madeira e mobiliário & 75.340 & 0 & 1.000 .613 & 1.093 .159 \\
Papel e gráfica & 178.365 & 0 & 564.199 & 748.487 \\
Indústria da borracha & 66.026 & 0 & 68.314 & 180.336 \\
Elementos químicos & 23.444 & 0 & 198.762 & 220.301 \\
Refino do petróleo & 79.352 & 0 & 646.219 & 872.171 \\
Químicos diversos & 40.019 & 0 & 84.664 & 191.217 \\
Farmacêutica e perfumaria & 12.017 & 0 & 2.385 .785 & 2.424 .284 \\
Artigos de plástico & 17.176 & 0 & 169.673 & 308.108 \\
Indústria textil & 101.246 & 0 & 1.150 .779 & 1.360 .054 \\
Artigos do vestuário & 3.885 & 0 & 2.024 .902 & 2.028 .826 \\
\hline
\end{tabular}


Tabela 7

Incidência final: ICMS (em R\$ mil) - Brasil, 1995

continuação

\begin{tabular}{lrrrr}
\hline Atividade & Exportação & $\begin{array}{c}\text { Consumo da } \\
\text { administração } \\
\text { pública }\end{array}$ & $\begin{array}{c}\text { Consumo } \\
\text { das } \\
\text { famílias }\end{array}$ & $\begin{array}{c}\text { Total } \\
\text { demanda } \\
\text { final }\end{array}$ \\
\hline Fabricação de calçados & 63.745 & 0 & 916.005 & 1.008 .714 \\
Indústria do café & 218.093 & 0 & 293.277 & 510.815 \\
Beneficiamento de produtos vegetais & 202.682 & 0 & 1.705 .165 & 1.911 .346 \\
Abate de animais & 43.889 & 0 & 2.453 .082 & 2.595 .978 \\
Indústria de latićnios & 181 & 0 & 1.373 .893 & 1.396 .714 \\
Indústria de açúcar & 107.816 & 0 & 548.369 & 608.994 \\
Fabricação de óleos vegetais & 255.018 & 0 & 428.319 & 698.924 \\
Outros produtos alimentares & 62.030 & 0 & 4.420 .791 & 4.552 .707 \\
Indústrias diversas & 54.518 & 0 & 1.848 .379 & 1.939 .396 \\
Serviços industriais de utilidade pública & 0 & 0 & 2.290 .979 & 2.290 .979 \\
Construção civil & 0 & 0 & 0 & 0 \\
Comércio & 82.112 & 0 & 0 & 82.112 \\
Transportes & 199.219 & 0 & 1.275 .745 & 1.474 .964 \\
Comunicações & 2.980 & 0 & 1.540 .360 & 1.543 .340 \\
Instituições financeiras & 8.945 & 0 & 469.312 & 478.257 \\
Serviços prestados às famílias & 27.764 & 0 & 2.651 .687 & 2.679 .451 \\
Serviços prestados às empresas & 19.348 & 0 & 14.804 & 34.153 \\
Aluguel de imóveis & 57 & 0 & 1.389 .880 & 1.389 .937 \\
Administração pública & 0 & 2.079 .256 & 111 & 2.079 .368 \\
Serviços privados não-mercantis & 0 & 0 & 35.253 & 35.253 \\
\hline Total & 3.331 .239 & 2.079 .256 & 41.266 .227 & 48.072 .215 \\
\hline
\end{tabular}

Obs.: O "total" da demanda final inclui o item "variação de estoque". Portanto, asoma dos componentes da demanda final apresentados na tabela pode não coincidir com o resultado da coluna "total". 
Tabela 8

Alíquotas efetivas: todos os impostos indiretos (\%) - Brasil, 1995

\begin{tabular}{|c|c|c|c|c|}
\hline Atividade & Exportação & $\begin{array}{c}\text { Consumo da } \\
\text { administração } \\
\text { pública }\end{array}$ & $\begin{array}{l}\text { Consumo } \\
\text { das } \\
\text { famílias }\end{array}$ & $\begin{array}{c}\text { Total } \\
\text { demanda } \\
\text { final }\end{array}$ \\
\hline Agropecuária & 25,6 & 0,0 & 10,2 & 10,3 \\
\hline Extração de petróleo e gás & 10,4 & 0,0 & 0,0 & 15,8 \\
\hline Minerais não-metálicos & 22,9 & 0,0 & 48,3 & 41,9 \\
\hline Outros metalúrgicos & 14,2 & 0,0 & 38,4 & 32,3 \\
\hline Máquinas e tratores & 14,0 & 0,0 & 22,9 & 10,5 \\
\hline Material elétrico & 14,6 & 0,0 & 32,2 & 29,1 \\
\hline Equipamentos eletrônicos & 10,4 & 0,0 & 20,2 & 19,8 \\
\hline Automóveis, caminhões e ônibus & 11,8 & 0,0 & 30,1 & 28,9 \\
\hline Elementos químicos & 8,2 & 0,0 & 10,2 & 9,8 \\
\hline Refino do petróleo & 8,5 & 0,0 & 9,8 & 9,9 \\
\hline Químicos diversos & 12,4 & 0,0 & 20,0 & 20,4 \\
\hline Farmacêutica e perfumaria & 7,6 & 0,0 & 24,1 & 23,8 \\
\hline Artigos de plástico & 14,4 & 0,0 & 34,8 & 32,3 \\
\hline Indústria textil & 12,3 & 0,0 & 28,7 & 25,7 \\
\hline Artigos do vestuário & 4,5 & 0,0 & 17,5 & 17,4 \\
\hline
\end{tabular}


Tabela 8

Alíquotas efetivas: todos os impostos indiretos (\%) - Brasil, 1995

continuação

\begin{tabular}{|c|c|c|c|c|}
\hline Atividade & Exportação & $\begin{array}{c}\text { Consumo da } \\
\text { administração } \\
\text { pública }\end{array}$ & $\begin{array}{l}\text { Consumo } \\
\text { das } \\
\text { famílias }\end{array}$ & $\begin{array}{c}\text { Total } \\
\text { demanda } \\
\text { final }\end{array}$ \\
\hline Fabricação de calçados & 6,4 & 0,0 & 27,2 & 20,6 \\
\hline Beneficiamento de produtos vegetais & 22,8 & 0,0 & 24,0 & 23,8 \\
\hline Abate de animais & 5,3 & 0,0 & 15,5 & 14,9 \\
\hline Indústria de laticínios & 7,8 & 0,0 & 17,1 & 17,1 \\
\hline Fabricação de óleos vegetais & 10,9 & 0,0 & 13,8 & 12,6 \\
\hline Outros produtos alimentares & 9,2 & 0,0 & 25,5 & 24,9 \\
\hline Indústrias diversas & 13,3 & 0,0 & 36,0 & 34,1 \\
\hline Serviços industriais de utilidade pública & 0,0 & 0,0 & 23,0 & 23,0 \\
\hline Construção civil & 0,0 & 0,0 & 0,0 & 0,0 \\
\hline Comércio & 47,9 & 0,0 & 0,0 & 47,9 \\
\hline Serviços prestados às famílias & 5,2 & 0,0 & 8,4 & 8,3 \\
\hline Serviços prestados às empresas & 8,0 & 0,0 & 8,0 & 8,0 \\
\hline Aluguel de imóveis & 4,3 & 0,0 & 4,2 & 4,2 \\
\hline Administração pública & 0,0 & 2,9 & 2,9 & 2,9 \\
\hline Serviços privados não-mercantis & 0,0 & 0,0 & 0,7 & 0,7 \\
\hline Total & 11,7 & 2,9 & 16,2 & 12,9 \\
\hline
\end{tabular}

Obs.: O "total" da demanda final inclui o item "variação de estoque". Portanto, asoma dos componentes da demanda final apresentados na tabela pode não coincidir com o resultado da coluna "total". 
Tabela 9

Alíquotas efetivas: ICMS (\%) - Brasil, 1995

\begin{tabular}{lrcrr}
\hline Atividade & Exportação & $\begin{array}{c}\text { Consumo da } \\
\text { administração } \\
\text { pública }\end{array}$ & $\begin{array}{c}\text { Consumo } \\
\text { das } \\
\text { famílias }\end{array}$ & $\begin{array}{c}\text { Total } \\
\text { demanda } \\
\text { final }\end{array}$ \\
\hline Agropecuária & 23,0 & 0 & 7,9 & 8,0 \\
Extrativa mineral & 3,4 & 0 & 0,0 & 3,9 \\
Extração de petróleo e gás & 2,5 & 0 & 0,0 & 2,2 \\
Minerais não-metálicos & 17,6 & 0 & 38,8 & 33,5 \\
Siderurgia & 4,7 & 0 & 0,0 & 5,8 \\
Metalurgia não-ferrosos & 4,5 & 0 & 18,7 & 8,1 \\
Outros metalúrgicos & 8,2 & 0 & 23,8 & 19,9 \\
Máquinas e tratores & 6,1 & 0 & 11,4 & 4,1 \\
Material elétrico & 7,4 & 0 & 17,4 & 15,7 \\
Equipamentos eletrônicos & 4,8 & 0 & 11,7 & 11,3 \\
Automóveis, caminhões e ônibus & 7,1 & 0 & 17,1 & 16,5 \\
Outros veículos e peças & 7,9 & 0 & 19,7 & 13,5 \\
Madeira e mobiliário & 5,9 & 0 & 15,4 & 13,8 \\
Papel e gráfica & 7,1 & 0 & 13,9 & 11,3 \\
Indústria da borracha & 12,1 & 0 & 30,4 & 19,6 \\
Elementos químicos & 3,6 & 0 & 6,0 & 5,5 \\
Refino do petróleo & 4,2 & 0 & 5,8 & 5,8 \\
Químicos diversos & 6,2 & 0 & 11,4 & 11,3 \\
Farmacêutica e perfumaria & 4,0 & 0 & 16,7 & 16,5 \\
Artigos de plástico & 7,8 & 0 & 19,9 & 18,3 \\
Indústria textil & 8,9 & 0 & 24,5 & 21,6 \\
Artigos do vestuário & 2,8 & 0 & 15,1 & 15,0 \\
\hline
\end{tabular}


Tabela 9

Alíquotas efetivas: ICMS (\%) - Brasil, 1995

continuação

\begin{tabular}{lcccc}
\hline Atividade & Exportação & $\begin{array}{c}\text { Consumo da } \\
\text { administração } \\
\text { pública }\end{array}$ & $\begin{array}{c}\text { Consumo } \\
\text { das } \\
\text { famílias }\end{array}$ & $\begin{array}{c}\text { Total } \\
\text { demanda } \\
\text { final }\end{array}$ \\
\hline Fabricação de calçados & 3,4 & 0 & 22,8 & 16,7 \\
Indústria do café & 9,7 & 0 & 9,7 & 9,7 \\
Beneficiamento de produtos vegetais & 8,2 & 0 & 9,5 & 9,3 \\
Abate de animais & 3,5 & 0 & 13,8 & 13,2 \\
Indústria de latićnios & 3,3 & 0 & 14,9 & 14,9 \\
Indústria de açúcar & 6,1 & 0 & 30,0 & 17,6 \\
Fabricação de óleos vegetais & 8,5 & 0 & 11,4 & 10,2 \\
Outros produtos alimentares & 6,0 & 0 & 18,6 & 18,1 \\
Indústrias diversas & 8,2 & 0 & 25,6 & 24,2 \\
Serviços industriais de utilidade pública & 0,0 & 0 & 21,7 & 21,7 \\
Construção civil & 0,0 & 0 & 0,0 & 0,0 \\
Comércio & 24,2 & 0 & 0,0 & 24,2 \\
Transportes & 5,8 & 0 & 10,2 & 9,2 \\
Comunicações & 9,1 & 0 & 27,6 & 27,4 \\
Instituições financeiras & 3,6 & 0 & 3,6 & 3,6 \\
Serviços prestados às famílias & 2,8 & 0 & 4,2 & 4,2 \\
Serviços prestados às empresas & 1,5 & 0 & 1,5 & 1,5 \\
Aluguel de imóveis & 2,4 & 0 & 2,4 & 2,4 \\
Administração pública & 0,0 & 1,6 & 1,6 & 1,6 \\
Serviços privados não-mercantis & 0,0 & 0 & 0,5 & 0,5 \\
\hline Total & 6,7 & 1,6 & 10,7 & 8,4 \\
\hline
\end{tabular}

Obs.: O "total" da demanda final inclui o item "variação de estoque". Portanto, a soma dos componentes da demanda final apresentados na tabela pode não coincidir com o resultado da coluna "total". 
As tabelas 8 e 9 mostram que a alíquota efetiva média sobre as famílias é de 16,2\% para o total dos impostos indiretos e de 10,7\% para o ICMS. Para alguns produtos, inclusive bens considerados essenciais, tais como alimentação e vestuário, as famílias se deparam com alíquotas efetivas bastante superiores a essas médias. Por exemplo, a tabela 8 mostra que sobre produtos vegetais beneficiados (que incluem arroz e farinha de trigo) incide uma alíquota efetiva média de $24,0 \%$, enquanto para "outros produtos alimentares" (inclusive bebidas) a alíquota efetiva média é de $25,5 \%$. Pode-se constatar, ainda, que a alíquota efetiva média sobre artigos do vestuário é de 17,5\% e a incidente sobre fabricação de calçados é de $27,2 \%$. Para os bens mencionados, as altas alíquotas efetivas refletem principalmente altas alíquotas de primeiro estágio, como pode ser observado comparando-se as tabelas 8 e 9 com as tabelas 4 e 5 , respectivamente.

Por outro lado, as exportações, que aparentemente eram apenas levemente tributadas, com alíquotas de primeiro estágio de $2,5 \%$ e 1,4\% para todos os impostos e para o ICMS, respectivamente, eram de fato fortemente oneradas pelos impostos indiretos em 1995, com uma alíquota média efetiva de 11,7\% para o total dos impostos e de $6,7 \%$ para o ICMS. Comparando-se as tabelas 8 e 9 com as tabelas 4 e 5, observa-se que, mesmo que não haja incidência direta de impostos sobre as exportações de produtos agropecuários e produtos vegetais beneficiados, conforme a Lei Kandir, ${ }^{16}$ as exportações serão substancialmente afetadas pela tributação direta e indireta de insumos.

Note-se que, conceitualmente, as alíquotas na última coluna da tabela 8 correspondem aos impostos efetivos apresentados na tabela 2 de Sampaio de Souza (1996). No entanto, não é possível uma comparação detalhada entre os resultados dos dois estudos, visto que as atividades de produção estão agregadas em apenas 18 categorias na apresentação de Sampaio de Souza. Todavia, pode-se observar que para as categorias coincidentes nos dois trabalhos, como borracha e têxteis, ${ }^{17}$ as alíquotas efetivas deste artigo são bem superiores àquelas estimadas em Sampaio de Souza. Esta discrepância pode estar associada a diferenças metodológicas tanto no cálculo da incidência final

\footnotetext{
${ }^{16}$ Ver nota 13.

${ }^{17}$ As outras categorias coincidentes são: "madeira e mobiliário", "farmacêutica e perfumaria" e "papel e gráfica".
} 
dos impostos quanto na estimação da incidência nominal (ou estatutária) ${ }^{18} \mathrm{e}$, ainda, ao fato de que os dados utilizados por Sampaio de Souza se referem 1980 .

\section{Comentários Finais}

Devido à multiplicidade de impostos e alíquotas e à incidência sobre insumos, o efeito final do sistema de impostos indiretos no Brasil sobre os preços para o consumidor está longe de ser transparente. Usando um método que incorpora os efeitos multissetoriais dos impostos indiretos, estimamos o efeito da tributação de bens intermediários sobre a tributação de bens finais.

Os resultados indicam que a incidência efetiva dos impostos é bem diversa daquela defendida pelos formuladores de políticas econômicas ou desejada pela sociedade, revelando que o governo está, de fato, tributando pesadamente bens que intenciona isentar ou tributar apenas levemente. Isso ocorre, por exemplo, com as exportações, que, apesar de existir uma política explícita de desoneração das mesmas, são implicitamente tributadas devido aos impostos cobrados sobre insumos usados na produção de bens e serviços exportados. Neste caso, os impostos efetivos oferecem uma estimativa da tributação indireta embutida nos bens exportados, que pode ser útil na determinação do nível apropriado de rebates compensatórios para exportações. ${ }^{19}$

Observou-se também que as alíquotas efetivas sobre bens que representam uma grande parcela no orçamento das famílias de baixa renda, tais como alimentos e vestuário, revelaram-se ainda mais altas do que as alíquotas nominais implícitas nas receitas arrecadadas. ${ }^{20}$ Vale ainda notar que as alíquotas efetivas evidenciam a grande dispersão da incidência dos impostos indiretos sobre os vários bens e serviços, o que geralmente é considerado indesejado do ponto de vista de eficiência econômica. ${ }^{21}$

\footnotetext{
${ }^{18}$ Enquanto neste artigo a incidência nominal é obtida diretamente da matriz de insumoproduto de 1995, no estudo de Sampaio de Souza ela é derivada a partir da reconciliação de informações contidas na matriz de 1980, nos anuários fiscais e no anuário de comércio exterior.

${ }^{19}$ As regras da OMC permitem tais compensações. O argumento implícito é de que impostos sobre insumos são transferidos para os bens finais.

${ }^{20}$ A distribuição da carga dos impostos indiretos entre as famílias no Brasil é analisada em Siqueira et alii (no prelo).

${ }^{21}$ Note-se, no entanto, que a estrutura ótima de impostos não é necessariamente uniforme. Ver Siqueira (1998) sobre impostos ótimos para o Brasil.
} 
Por último, na interpretação dos resultados aqui apresentados, deve-se ter em mente dois pontos importantes. Primeiro, existem outros impostos no Brasil que oneram a produção e o consumo e que não estão incluídos na matriz de insumo-produto, como, por exemplo, a contribuição para o financiamento da seguridade social (Cofins), a contribuição para o programa de integração social (PIS) e a contribuição provisória sobre movimentações financeiras (CPMF). ${ }^{22}$ Portanto, mesmo levando em conta que os efeitos da Lei Kandir $^{23}$ também não estão incorporados na matriz de 1995, é provável que a carga tributária indireta esteja sendo subestimada neste artigo. Segundo, as estimativas aqui apresentadas estão baseadas na hipótese de que todos os impostos indiretos são totalmente transferidos para a demanda final. Conforme observado por Scutella (1997), essa suposição talvez não se aplique de forma geral, visto que algumas atividades podem não ser capazes de transferir os impostos para seus consumidores.

\section{Referências Bibliográficas}

Ahmad, E. \& Stern, N. Alternative sources of government revenue: examples from India, 1979-80. In: Newbery, D. \& Stern, N. The theory of taxation for developing countries. Oxford, Oxford University Press, 1987.

$\&$ - The theory and practice of tax reform in developing countries. Cambridge, Cambridge University Press, 1991.

Atkinson, A. Optimal taxation and the direct versus indirect tax controversy. Canadian Jorunal of Economics, 10(4), 1977.

Chisholm, A. Indirect taxation and consumption efficiency. In: Head, J. (ed.). Fightback: an economic assessment. Sidney, Australian Tax Research Foundation, 1993.

Creedy, J. The welfare effects of indirect taxes in Australia: some alternative reforms. Department of Economics, University of Melbourne, 1998. (Research Paper, 601.)

\footnotetext{
${ }^{22} \mathrm{O}$ método utilizado neste artigo permite introduzir esses impostos na análise, requerendose apenas informação sobre a arrecadação de cada imposto por setor de atividade e sobre a existência de isenções.

${ }^{23}$ Ver nota 13.
} 
Engel, E. et alii. Taxes and income distribution in Chile: some unpleasant redistributive arithmetic. Cambridge, National Bureau of Economic Research, 1998. (http://www.nber.org/papers/w6828.)

Eris, I. et alii. A distribuição de renda e o sistema tributário brasileiro. In: Eris, C. et alii. Finanças públicas. São Paulo, Pioneira, 1983.

IBGE. Matriz de insumo-produto: Brasil 1995. Rio de Janeiro, IBGE, 1997.

Mas-Colell, A.; Whinston, M. \& Green, J. Microeconomic theory. Oxford, Oxford University Press, 1995.

Pechman, J. Who paid the taxes, 1966-85. Washington, D.C., Brookings Institution, 1985.

Sanson, J. R. An alternative model for studying the incidence of indirect taxes. Journal of Public Economics, 25, 1984.

Scutella, R. Calculating the final incidence of Australian indirect taxes. Melbourne Institute of Applied Economic and Social, University of Melbourne, 1997. (Working Paper, 18/97.)

Siqueira, R. Optimal indirect taxes for Brazil: combining equity and effficiency. Revista Brasileira de Economia, 52(1), jan/mar. 1998.

et alii. Os impostos sobre consumo no Brasil são regressivos?

Economia Aplicada, 4(4), out/dez. 2000.

Souza, M. C. Sampaio de. Tributação indireta no Brasil: eficiência versus equidade. Revista Brasileira de Economia. Rio de Janeiro, FGV, 50(1), jan/mar. 1996.

Stern, N. Aspects of the general theory of tax reform. In: Newbery, D. \& Stern, N. The theory of taxation for developing countries. Oxford, Oxford University Press, 1987.

Younger, S. et alii. Tax incidence in Madagascar: an analysis using household data. The World Bank Economic Review, 13(2), 1999.

Whalley, J. Regression or progression: the taxing question of incidence analysis. Canadian Journal of Economics, 17(4), 1984. 